\title{
Japan placates fishermen after launch delay
}

Tokyo. Japan's ambitions to become a major player in commercial space activities received a boost last Saturday (18 March) with the successful launch of two large payloads by its new H-II rocket. The launch, which had been delayed several weeks because of technical problems, will help to restore confidence in the $\mathrm{H}-\mathrm{II}$, which was dented by the failure of its second mission last August (Nature, 371, 92: 1995).

The rocket successfully placed a geostationary weather satellite in transfer orbit. It also released a reusable orbital platform, the Space Flyer Unit (SFU), which has been designed to carry out various scientific experiments before being recaptured by the US space shuttle in November.

The SFU, which cost $¥ 41.8$ billion (nearly US $\$ 0.5$ billion) to develop, is a huge joint mission involving three different government organizations, and thus represents a rare example of collaboration in research between different arms of the government.

The agencies involved are the Institute of Space and Astronautical Science (ISAS) of the Ministry of Education, Science and Culture, the National Space Development Agency (NASDA), which is affiliated with the Science and Technology Agency, and the New Energy and Industrial Technology Development Organization (NEDO) which operates under the powerful Ministry of
International Trade and Industry.

The platform was due to be boosted on 21 March from a height of about $330 \mathrm{~km}$ to a higher operational orbit of $500 \mathrm{~km}$. It carries an exposed section on which NASDA is planning to test equipment and materials intended for the Japanese Experiment Module of the US space station.

ISAS, which is responsible for tracking the SFU, has several experiments on board. These include an infrared telescope, a high voltage solar array designed to verify that changing the connections between solar cells can alter its output, and an experimental electric propulsion system called the Magneto-PlasmaDynamic thruster.

Other experiments inc-

Japan's Space Flyer Unit: a successful example of interministerial cooperation. series of delays because of problems with the SFU and other components. As a result, NASDA was put in the unusual position of having to negotiate with local fishermen to allow the launch to proceed.

This resulted from an earlier agreement reached with about 10,000 fishermen in five prefectures adjacent to NASDA's launch centre in Tanegashima island off Japan's southern island of Kyushu. Under the terms of the agreement, NASDA pays about $¥ 600$ million ( $\$ 6$ million) a year to fishing cooperatives for permission to launch during two twomonth periods, in summer and in winter.

As this week's launch was outside the January-February window, NASDA had to lude a facility for crystal growth experiments under conditions of microgravity, and a container with newts that will be used to test the effects of zero gravity on egg laying and hatching. NEDO has three electric furnaces aboard the platform to grow semiconductor crystals and thin films under microgravity conditions.

The launch was originally planned for the beginning of February, but experienced a strike a special one-off deal with the fishermen, who claim the launches disrupt their activities. NASDA will not say how much was paid, as it varied from cooperative to cooperative. The restriction on two launch windows a year remains, and the agency will have to reach a long-term agreement with the fishermen if it is to become a serious competitor in the world market for commercial satellite launches. David Swinbanks

\section{Grant challenges role of peer review in an age of e-mail}

London. The US National Science Foundation (NSF) has awarded a grant of more than US\$1 million to Paul Ginsparg, a high-energy physicist at the Los Alamos National Laboratories in New Mexico, to expand his electronic archive of research articles and preprints.

Ginsparg set up the archive, initially specializing in high-energy physics, in 1991. It now includes 25 other disciplines and is consulted more than $\mathbf{4 5 , 0 0 0}$ times a day by scientists worldwide, wishing to find or to contribute new items. But it has also raised controversy by challenging the conventional practice of publishing papers only when they have been peer-reviewed.

Researchers are able to send in articles or preprints in relevant subject areas. Once the papers are in electronic format, Ginsparg provides cross-references. He says that his archive differs from computer bulletin boards and news groups in that it is a "formal mode of communication in which each entry is archived and indexed for later retrieval".

Richard Isaacson, programme director for gravitational physics at the NSF, describes Ginsparg's database as "an unusual and unique service" that has "already become the most interesting stop on the infobahn for a large part of the theoretical physics community".

The purpose of the grant, which has come from both the NSF's physics budget and an Office of Multi-Disciplinary Activities created last November to support innovative projects, is to allow Ginsparg - who has so far been developing the database on a part-time basis - to take on full-time professional software support.

The main novelty of Ginsparg's system over the conventional form of informal electronic communication between scientists is that it allows public commentaries to be added to papers, an approach that could take the place of traditional refereeing.

Some see this as a direct threat to the peer-review process used by traditional printed journals. "Publishers might not like what is happening," Ginsparg acknowledges. "But the effort to change the manner in which research is communicated is being driven by the researchers."

Most academic publishers are already anticipating a gradual shift from paper to electronic archives of publications. But there is still much heated debate about the implications of the traditional process of refereeing and editing papers before publication being replaced by Ginsparg's vision of "interactive journals".

Ginsparg himself says that he hopes his archive will support what he describes as a "virtual corridor", where a scientist will be able to work down the hallway and talk to fellow researchers.

At the same time, publishers themselves are considering how to build an electronic infrastructure to suit researchers' needs. Last month, for example, the publishing company Elsevier Science launched a pilot scheme to investigate how electronic subscriptions can be used.

Roland Dietz, senior vice president of EIsevier Science, New York, says that research institutions in both the academic and industrial sector are at a wide variety of stages of development. "Some already have internal systems in place, others are much less advanced."

But Dietz says that all recognize that the potential is enormous. He says that electronic libraries will be able to store information locally, make it available to researchers at their desktops, set up security systems and allow users to $\log$ on from home or a conference. Fiona Gammie 